OPEN ACCESS

Edited by:

Lars Ditlev Morck Ottosen, Aarhus University, Denmark

Reviewed by: Alok Satlewal,

Indian Oil Corporation, India Ruchi Agrawal,

Indian Oil Corporation, India

${ }^{*}$ Correspondence: Michael Siegert michae/@siegert.org

Specialty section:

This article was submitted to Bioenergy and Biofuels, a section of the journal Frontiers in Energy Research

Received: 19 September 2018 Accepted: 19 November 2018 Published: 30 November 2018

Citation:

Siegert M (2018) A Scalable Multi-Channel Software Potentiostat.

Front. Energy Res. 6:131. doi: 10.3389/fenrg.2018.00131

\section{A Scalable Multi-Channel Software Potentiostat}

\author{
Michael Siegert* \\ Independent Investigator, Chicago, IL, United States
}

Electronic hardware is a major cost driver when scaling bio-electrical systems (BES) for biological methanation. Many academic publications reporting BES experiments lack statistical power because such experiments are seldom carried out in replicates. One reason is that conventional electronic potentiostats often lack sufficient independent channels required for replication. Nonetheless, replication is necessary for any statistical analysis. Here, I developed a simple, easy-to-scale multi-channel software potentiostat which solves these problems. The software controls off-the-shelf hardware saving up to $80 \%$ of the hardware cost spent otherwise for electronic potentiostats. The difference between the setpoint and the measured working electrode potential was comparable to that of hardware potentiostats. Chronoamperomtric experiments were carried out in parallel for 10 days at $+0.300 \mathrm{~V}$ and $-0.800 \mathrm{~V}$. A scaling experiment using a tubular wastewater treatment reactor demonstrated that the software can be used to scale BES. The results show that a simple proportional controller can replace expensive potentiostats for chronoamperometry.

Keywords: potentiostat, bio-electrical system, electrolysis, microbial electrolysis cell, electrosynthesis, power-to-gas, proportional controller, cathodic protection

\section{INTRODUCTION}

Microbial power-to-gas uses microbial electrolysis cells (MEC) to convert electricity and $\mathrm{CO}_{2}$ into useful products such as methane, acetate, formic acid, syngas, 2-oxybutyrate, butyrate, ethanol, and butanol in a process called electrosynthesis (Bajracharya et al., 2017). This technology is also used commercially for wastewater treatment accelerating anaerobic digestion (AD) processes (Siegert et al., 2019). Commercial applications for wastewater treatment or electrosynthesis using MECs require cheap technology including control systems to poise the electrochemical potential at a desired setpoint. These devices are called potentiostats because they stabilize the electrochemical potential on at least one electrode. In microbial power-to-gas applications, methane is produced by hydrogenotrophic methanogens at electrode poised potentials ranging from $-0.4 \mathrm{~V}$ to $-1.5 \mathrm{~V}$ vs. a standard hydrogen electrode (SHE; Geppert et al., 2016). Scaling such control systems can be expensive if they must be tailored to each specific application in each scaling step. Previously, an inexpensive electronic potentiostat was developed to monitor microbial respiration at a price of $\$ 600$ (Friedman et al., 2012). However, the electronics were not scalable beyond $\mathrm{mW}$ nor were the number of channels except when stacking such devices. Here, I use a simple proportional controller software that makes tailored hardware development of potentiostats for chronoamperometry obsolete because off-the-shelf electronics can be purchased and controlled by this algorithm. This algorithm would lead to better economic feasibility. 


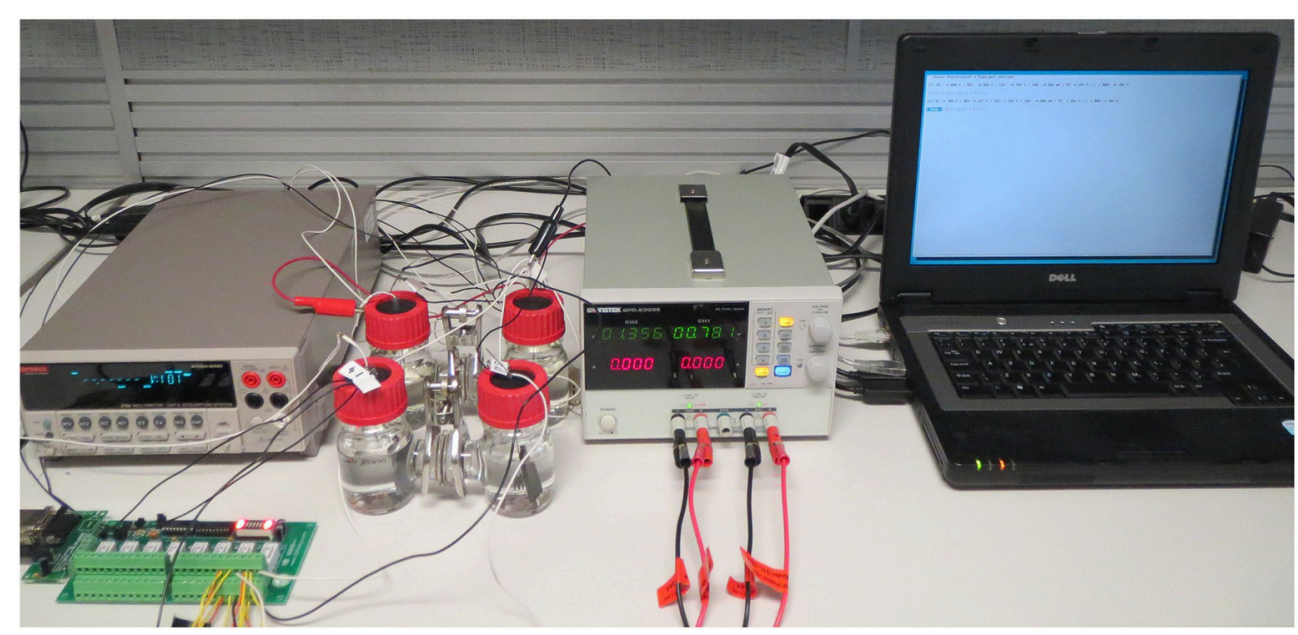

FIGURE 1 | Complete experimental setup with two potentiostat channels. From left to right: digital multimeter (in the back), relay board (in front), two H-type electrolysis cells, power supply, control computer.

The development of MECs suffers from lacking replication. Most literature in this field is published using only single treatment and control. In contrast, there are often stark differences between replicates which makes the comparison of treatment and control experiments often impossible (Siegert et al., 2014). The reason for the absence of statistical robustness is simply the economic constrains which nearly all research labs face. However, it is possible to conduct high throughput bio-electrical experiments using inexpensive multi-channel equipment that allows appropriate statistical analysis (Call and Logan, 2011). The proportional controller developed in this study allows the use of unlimited potentiostat channels for up to $80 \%$ cost saving in lab equipment. The algorithm is based on the simple rule of proportion as it is taught everywhere in school mathematics.

\section{MATERIALS AND METHODS \\ MEC Reactors}

Two types of electrolysis cells were tested. First, a simple Hcell without membrane, containing a $3 \mathrm{M} \mathrm{NaCl}$ solution was used as I have described it previously (Siegert et al., 2014). The cell contained $200 \mathrm{ml}$ of said solution with a headspace of about $50 \mathrm{ml}$ in each of the two chambers. Graphite block electrodes $(1 \times 4 \times 0.32 \mathrm{~cm})$ connected to titanium wires catalyzed the electrolysis reaction. $\mathrm{An} \mathrm{Ag} / \mathrm{AgCl}$ electrode (model RE-5B, BASi, West Lafayette, IN, U.S.A.) served as reference for one of the graphite electrodes. In $3 \mathrm{M} \mathrm{NaCl}$, the offset potential of an SHE electrode to an $\mathrm{Ag} / \mathrm{AgCl}$ electrode is about $+0.21 \mathrm{~V}$. Two tests were run using $\mathrm{H}$-cells, one at a setpoint of $+0.300 \mathrm{~V}$ and the other at a setpoint of $-0.800 \mathrm{~V}$. Both reactors were operated independently for 10 days, using two channels of the same power supply. To test the scalability of the software, a 71 tube reactor was built from a steel stove pipe (purchased at a Canadian Tire hardware store). The stove pipe served as outer electrode and was poised at $-0.8 \mathrm{~V}$ to be the cathode. The second electrode was coiled 304 steel mesh inserted into the outer electrode. The $\mathrm{Ag} / \mathrm{AgCl}$ reference electrode was taped to the outer electrode using electrical tape and completely submersed in the electrolyte. Gas was collected in three 11 gas-tight gas bags (Restek, State College, PA, USA) but its volume and composition was not determined. Wastewater enriched with $1 \%_{\mathrm{v} / \mathrm{v}}$ AD sludge from Calgary's Fish Creek wastewater treatment plant was circulated through the tube reactor using a peristaltic pump. The reactor was operated for 9 days.

\section{Control Electronics}

All components were connected to the same laptop computer using its USB ports. The cell voltages were controlled using computer-programmable power supplies (GW-Instek GPD2303S, Tradeport Electronics Group, Concord, ON, Canada) connected to a computer via USB cables. Voltage readings were recorded using a digital multimeter (DMM; model Keithley 2700, Tektronix, Inc., Beaverton, OR, USA) with a 20-channel multiplexer board (model Keithley 7700, also Tektronics Inc.) connected via its RS232 port and a USB-to-serial adapter using an FTDI converter chip (FTDI2232, Future Technology Devices International, Glasgow, United Kingdom). To switch the polarity of the cells, an RS232 8-channel double-pull double-throw relay board was used (model R81DPDTCN, National Control Devices, Osceola, MO, USA). The relay board was also connected using an FTDI adapter cable. To calculate the current, resistors were connected to the counter electrode. The resistances were $0.5 \Omega$ for the $+0.300 \mathrm{~V}$ and $1.0 \Omega$ for the $-0.800 \mathrm{~V} \mathrm{H}$-cell tests, and $1.0 \Omega$ for tube reactor experiment. The complete setup is shown in Figure 1.

\section{Algorithm}

The instrumental setup was controlled using a simple algorithm based on the rule of proportion (Equation 1) 


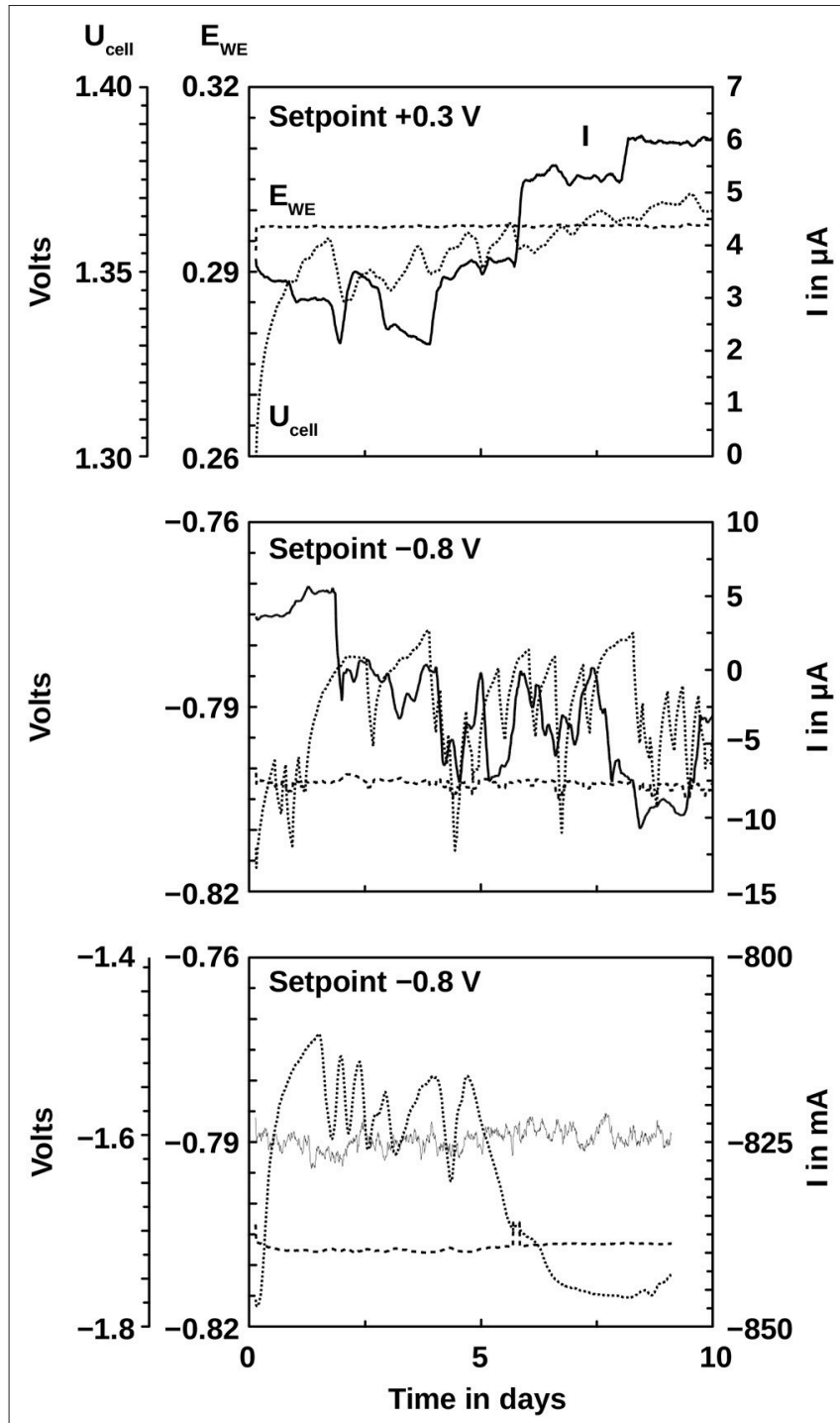

FIGURE 2 | Results of three test runs of the potentiostat software with different setpoints: top setpoint $+0.300 \mathrm{~V}$ in one $\mathrm{H}$-cell, middle setpoint $-0.800 \mathrm{~V}$ in the other $\mathrm{H}$-cell, bottom setpoint $-0.800 \mathrm{~V}$ in a $7 \mathrm{I}$ tube reactor; $U_{\text {cell }}$, measured cell voltage, $E_{W E}$, measured working electrode potential.

and implemented using the programming language Java:

$$
\frac{U_{m}}{E_{m}}=\frac{U_{n}}{E_{S P}}
$$

where $U_{m}$ is the last measured cell voltage and $U_{n}$ is the next cell voltage to be set. $E_{m}$ is the measured electrode potential relative to a reference electrode and $E_{S P}$ is the desired setpoint potential. The code to find $U_{n}$ was looped while $U_{m}$ and $E_{m}$ were continuously scanned. A full DMM scan lasted $\sim 7 \mathrm{~s}$, which was also the highest possible measurement frequency. The polarity was switched if necessary using the connected relay. The Linux version of the software is available under this link https://frontis-energy.com/wp-content/uploads/2018/ 04/Frontcell.zip.

\section{RESULTS AND DISCUSSION}

Test runs at positive and negative poised potentials showed that the software potentiostat was stable compared with electronic potentiostats (Figure 2). The average measured potential against the reference electrode for the setpoint of $+0.300 \mathrm{~V}$ was $+0.297 \pm$ $0.006 \mathrm{~V}\left(n=13,766 ; \sigma^{2}=3.8 \times 10^{-5}\right)$. For the negative setpoint of $-0.800 \mathrm{~V}$ it was $-0.802 \pm 0.005 \mathrm{~V}\left(n=13,766 ; \sigma^{2}=3.0 \times\right.$ $10^{-5}$ ). The currents recorded were in the range of +2 to +6 $\mu \mathrm{A}$ for the positive setpoint and -10 to $+5 \mu \mathrm{A}$ or the negative setpoint. Both, the working electrode potential and the current were in the expected range for this size and type of electrodes and comparable to commercial potentiostats (Friedman et al., 2012).

To test the scalability of the setup, a 71 tube reactor was operated with wastewater as an electrolyte. The software stabilized the working electrode potential in this reactor type as expected (Figure 2). The average measured working electrode potential was $-0.807 \pm 0.006 \mathrm{~V}\left(n=13,004 ; \sigma^{2}=3.6 \times 10^{-5}\right)$. However, the applied cell voltage between the inner and the outer electrodes was about double compared with the $\mathrm{H}$-cell. One possible reason might be the higher Ohmic resistance of the wastewater electrolyte (not determined) compared with the $3 \mathrm{M}$ $\mathrm{NaCl}$ solution used in the $\mathrm{H}$-cells. As expected for the greater volume, electrode surface, and electron donor supply, the current recorded by the multimeter was orders of magnitude higher than in the H-cells and circulated around $-825 \mathrm{~mA}$. In contrast, the current recorded from the power supply reading was about five times lower $(\sim 150 \mathrm{~mA})$ compared to that recorded by the multimeter. This discrepancy was possibly due to corrosion of the steel anode as well as the organic load of the wastewater. The power supply only measures the current it consumes while the current through the resistor reflects the current running through the entire cell.

In conclusion, the proportional controller I present here can be used to scale BES in both, breadth (channels) and depth (current) with the potential of reducing the cost of BES.

\section{AUTHOR CONTRIBUTIONS}

MS invented the algorithm, programmed the code, tested the software, designed the experiments, collected the data, prepared all figures, and wrote the manuscript.

\section{FUNDING}

Parts of this research were funded by the University of Calgary Eyes High Postdoctoral Fellowship.

\section{ACKNOWLEDGMENTS}

I thank Calgary's Fish Creek Wastewater Treatment Plant staff for being always supportive. Dr. John Pisciotta of the West Chester University of Pennsylvania helped with reviewing the manuscript and with the English language. 


\section{REFERENCES}

Bajracharya, S., Srikanth, S., Mohanakrishna, G., Zacharia, R., Strik, D., and Pant, D. (2017). Biotransformation of carbon dioxide in bioelectrochemical systems: state of the art and future prospects. J. Power Sources 356, 256-273. doi: 10.1016/j.jpowsour.2017.04.024

Call, D. F., and Logan, B. E. (2011). A method for high throughput bioelectrochemical research based on small scale microbial electrolysis cells. Biosens Bioelectron 26, 4526-4531. doi: 10.1016/j.bios.2011.05.014

Friedman, E. S., Rosenbaum, M. A., Lee, A. W., Lipson, D. A., Land, B. R., and Angenent, L. T. (2012). A cost-effective and field-ready potentiostat that poises subsurface electrodes to monitor bacterial respiration. Biosens Bioelectron 32, 309-313. doi: 10.1016/j.bios.2011.12.013

Geppert, F., Liu, D., van Eerten-Jansen, M., Weidner, E., Buisman, C., and Ter Heijne, A. (2016). Bioelectrochemical power-to-gas: state of the art and future perspectives. Trends Biotechnol. 34, 879-894. doi: 10.1016/j.tibtech.2016.08.010

Siegert, M., Sonawane, J. M., Ezugwu, C. I., and Prasad, R. (2019). "Economic assessment of nano-materials in bio-electrical water treatment," in Advanced
Research in Nanosciences for Water Technology eds R. Prasad and K. Thirugnanasanbandham (Cham: Springer Nature Switzerland AG), 1-22. doi: 10.1007/978-3-030-02381-2

Siegert, M., Yates, M. D., Call, D. F., Zhu, X., Spormann, A., and Logan, B. E. (2014). Comparison of nonprecious metal cathode materials for methane production by electromethanogenesis. ACS Sustain. Chem. Eng. 2, 910-917. doi: $10.1021 / \mathrm{sc} 400520 \mathrm{x}$

Conflict of Interest Statement: MS made a commercial version of the software named Frontcell ${ }^{\odot}$, available. A patent is pending on the algorithm and other parts of this research under PCT/IB2018/052671.

Copyright (c) 2018 Siegert. This is an open-access article distributed under the terms of the Creative Commons Attribution License (CC BY). The use, distribution or reproduction in other forums is permitted, provided the original author(s) and the copyright owner(s) are credited and that the original publication in this journal is cited, in accordance with accepted academic practice. No use, distribution or reproduction is permitted which does not comply with these terms. 